\title{
Franck Gaudichaud, Chile 1970-1973. Mil dias que estremecieron al mundo. Poder popular, cordones industriales y socialismo durante el gobierno de Salvador Allende, Santiago: LOM, 2016.
}

El llamado poder popular ha recibido mucha atención en comparación a otros procesos también relevantes ocurridos durante el gobierno de Salvador Allende en Chile. Por ello, la publicación de un nuevo libro sobre el tema difícilmente podría sumar nuevos elementos. Sin embargo, Franck Gaudichaud ofrece una bocanada de aire fresco. Además de profundizar y reformular el análisis de la antigua investigación de Hugo Cancino ( $L a$ problemática del poder popular en el proceso de la vía chilena al socialismo 1970-1973, Aarhus University, 1988), continúa extendiendo los estudios "desde abajo" de la experiencia obrera en los espacios industriales durante la Unidad Popular (UP), en la senda abierta por el clásico texto de Peter Winn (Tejedores de la Revolución. Los trabajadores de Yarur y la vía chilena al socialismo, LOM, 2004). La obra de Gaudichaud se cuida de ser solo un rescate testimonial, muy militante pero poco explicativo de esta experiencia, como han terminado siendo otras investigaciones (por ejemplo, Miguel Silva, Los Cordones Industriales y el socialismo desde abajo, 1999).

Este volumen, el más reciente de Gaudichaud (tesis doctoral del 2005 y de la cual ya publicó varias entrevistas en Poder popular y cordones industriales. Testimonios sobre el movimiento urbano chileno [LOM, 2004]), se compone de cuatro grandes apartados subdivididos en tres o cuatro capítulos cada uno. La primera parte aborda los elementos estructurantes del movimiento obrero nacional: las características socioeconómicas del país, las relaciones con el Estado y los partidos políticos, para terminar con la izquierda y su "via chilena al socialismo". Continúa indagando en la estrategia de la UP para desarrollar un "poder popular" institucionalizado, que generó tensiones y radicalización en la base social del gobierno, experimentando sus primeros desbordes "desde abajo". Luego analiza el paso de una zona industrial (cordón en sî) a un territorio de autoorganización y politización obrera (cordón para sî), proceso dinamizado por dos coyunturas nacionales clave (el paro de camioneros en octubre de 1972 y la "normalización" cívico-militar de la UP). Finalmente, profundiza en los repertorios del poder popular, viendo sus prácticas protestatarias (barricadas, formas de articulación territorial, etc.) y culturales (obras de teatro, canciones, periódicos, etc.) que se desplegaron al calor de la lucha.

Siendo parte del proceso de "revitalización de la historiografia política" chilena dada en la última década, donde el gobierno de Allende ha ocupado un lugar preferencial, la investigación es un aporte por varias razones. Primero, porque relee con un instrumental teórico multidisciplinar, que combina conceptos de un marxismo "heterodoxo" -conflictos de clase, experiencia y poder constituyente- con teorias de la sociología y ciencia política de raigambre francesa -acción colectiva y las políticas del conflicto-. Segundo, 
todo esto le sirven para comprender consistentemente un fragmentario proceso de autoorganización y politización obrera "desde abajo", tal como fue la experiencia del poder popular y los cordones industriales durante la UP. Tercero, porque su análisis se inscribe en una vertiente que conecta dialécticamente el movimiento social (poder popular) con los partidos políticos y el gobierno de Salvador Allende, en el marco de los conflictos de clases más general.

Este conjunto de elementos le permite al autor desarrollar un notable desplazamiento de "escalas", moviéndose desde las vivencias politicas de activista y/o militante "de base", hasta las estrategias y debates de los dirigentes partidarios. Y es al analizar esta compleja trama entre "lo social" y "lo político", donde se encuentra su principal tesis: el avance de proyecto político de la UP impulsó un proceso autoorganizativo "desde abajo" que no estaba contemplado por la izquierda chilena, desplegando una fuerza social que germinó un poder popular constituyente, en torno principal -aunque no únicamente- a los espacios de trabajo, es decir, los cordones industriales. Por ello, a pesar de su minúsculo desarrollo inicial y la oscilante participación posterior, la profundización del conflicto social potenció su expansión, convirtiéndolos en uno de los pocos sustentos del gobierno de Allende en sus momentos más críticos y en una de sus únicas posibilidades para resistir la ofensiva golpista hacia septiembre de 1973.

Aquí aparece una problemática clave para el análisis de los procesos de cambio revolucionario: la cuestión de la espontaneidad de las masas y las estrategias politicas. Siguiendo la investigación de Gaudichaud, se puede concluir que no todas las expresiones organizativas y políticas de los trabajadores son planificadas, sino que tienen una importante cuota de espontaneidad. Esta fuerza social puede desbordar las estrategias planificadas por los partidos y movimientos revolucionarios, poniendo en tela de juicio no solo la institucionalidad estatal, sino que también las mismas organizaciones de los grupos subalternos, tal como habria ocurrido con la Central Unitaria de Trabajadores (CUT) y los partidos de izquierda. Por lo mismo, para hacer la historia política del mundo obrero y popular se deben problematizar permanentemente los límites de lo institucionalizado, tratando de sumarse diversas aristas de estas experiencias, eso sí, sin dotarlas automática y mecánicamente de carácter politico y revolucionario. De igual forma, para el caso de la Unidad Popular, es necesario complementar estudios como éste, con aquellas formas de organización obrera y popular que se opusieron a Allende, donde incluso trabajadores protagonizaron resistencias a la estatización de sus fábricas. Ello, con el fin de ponderar la magnitud de estos procesos de politización.

En el fondo, Gaudichaud discute sobre la "dualidad de poderes" en los procesos de cambio social. Este debate tanto politico como teórico fundamental en las ciencias sociales y el marxismo contemporáneo ha planteado la posible estructuración de poderes paralelos entre la institucionalidad burguesa-capitalista y las organizaciones populares-subalternas. Ello ha 
derivado en algunos planteamientos que sostienen una posible situación de "doble poder" por períodos extensos de tiempo, distanciándose del carácter transitorio que le dio Lenin en base a la experiencia bolchevique. Para Gaudichaud, el "poder popular" chileno estuvo lejos de constituir un "doble poder", pues los comandos comunales -que fueron vistos por el MIR como posible encarnación de un poder paralelo- quedaron limitados, tanto por la débil participación de la base social a nivel territorial como por la intención de los partidos de la UP por acoplar esta fuerza activa a la transformación institucional que encabezaba Allende. En esta lógica, al menos para el caso analizado, cabría preguntarse si la categoría de poder popular constituyente es la más adecuada para distanciarse -tal como pretende Gaudichaud- de aquellos planteamientos que equiparan la autoorganización obrera con el poder estatal. Quizás sea mejor hablar de fuerza social constituyente, dado el carácter más líquido y oscilante, que se nutre de diversas experiencias fluidas, tal como remarca permanentemente el autor sobre el poder popular.

Con todo, el libro de Franck Gaudichaud es indispensable para el debate académico y político en Nuestra América, al ofrecer herramientas críticas para rescatar aquellos "tesoros" perdidos en el océano de la historia, que muchas veces las clases dominantes buscan sumergir y borrar del mapa, pero que permanecen en la memoria y pueden servir para comprender otros procesos similares, y -quizás más importantes aún-ser pistas para concretar las utopías de cambio social en el siglo XXI.

José Ponce (Universidad de Santiago de Chile)

$* * *$

\section{Kauan Willian dos Santos y Rafael Viana da Silva (orgs.), História do anarquismo e do sindicalismo de intenção revolucionária no Brasil. Novas perspectivas, Curitiba: Prismas, 2017, 449 pp.}

El interés historiográfico que despertó el anarquismo como tema de indagación en las últimas décadas produjo una renovada camada de estudios que permitieron poner de relieve ciertas aristas que habian quedado relegadas en investigaciones anteriores, donde el eje se centraba de forma exclusiva en la vida sindical. El libro compilado por Kauan Willian dos Santos y Rafael Viana da Silva, História do anarquismo e do sindicalismo de intenção revolucionária no Brasil, se propone contrarrestar los análisis unilaterales que se limitan sólo a la dimensión cultural de la experiencia anarquista, al considerar que derivan en un divorcio analítico entre los ideales libertarios y su dimensión de clase. En este sentido, retoman los estudios de esta corriente desde una perspectiva política y social, y ofrecen 